\title{
Current practicality of nanotechnology in dentistry. Part I: Focus on nanocomposite restoratives and biomimetics
}

This article was published in the following Dove Press journal:

Clinical, Cosmetic and Investigational Dentistry

27 November 2009

Number of times this article has been viewed

\author{
Scott A Saunders \\ MirrorMonitor Creativity, \\ Royersford, PA USA
}

Correspondence: Scott A Saunders Principal, MirrorMonitor Creativity, I0I 4 Andrew Way, Royersford, PA |9468-3|34, USA

Tel + I $610948200 \mid$

Fax + I 610948200

Email scott@mmcreativity.com

\begin{abstract}
First described in 1959 by physicist Richard P Feynman, who saw it as an unavoidable development in the progress of science, nanotechnology has been part of mainstream scientific theory with potential medical and dental applications since the early 1990s. Nanoparticles, nanospheres, nanorods, nanotubes, nanofibers, dendrimers and other nanostructures have been studied for various applications to biologic tissues and systems. While many layers of nanotechnologic capability have been envisioned for oral health in the last decade (eg, oral hygiene maintenance, local anesthesia, even whole-tooth replacement), few of these applications have been developed. Part 1 of a three-part series reviews the current clinical utility of nanotechnology's most tangible contribution to dentistry to date: the restoration of tooth structure with nanocomposites. Characterized by filler-particle sizes of $\leq 100 \mathrm{~nm}$, these materials can offer esthetic and strength advantages over conventional microfilled and hybrid resin-based composite (RBC) systems, primarily in terms of smoothness, polishability and precision of shade characterization, plus flexural strength and microhardness similar to those of the better-performing posterior RBCs. Available comparative data for nanocomposites and organically-modified ceramic $\left(\right.$ Ormocer $\left.^{\circledR}\right)$ restoratives are also reviewed. Finally, plausible "next-phase" trends in current nanorestorative research are judiciously examined, including 1) calcium-, phosphate-, and fluoride-ion-releasing nanocomposites for anticaries applications and 2) restorative systems based on biomimetic emulation of the nanomolecular assembly processes inherent in dental enamel formation using nanorods, nanospheres, and recombinant amelogenins.
\end{abstract}

Keywords: nanostructure, dental restorative, resin-based composite, biomimetic, amelogenin

\section{Introduction}

Nanotechnology in medicine has been recently reviewed (2002-present) from various perspectives relative to the human molecule-tissue interface. ${ }^{1-4} \mathrm{~A}$ common trend in this ongoing discussion is the capability to operate on a scale small enough to interact with intracellular components including DNA. ${ }^{5-8}$

Operating on a stage this minute provides a perspective to envision restoring tooth structure at a level that offers progressively closer approximation of its individual anatomic structures. The ever-shrinking size of the nanoparticles in resin-based composite (RBC) ceramic restorative systems continues in a progression that might be envisioned as "mimicking" actual tooth structure.

Following this progression at the nanoscale, current laboratory-bench dental research is exploring designs for restorative systems that biomimetically approximate the very processes by which dental enamel is formed. ${ }^{9-12}$ Admittedly, this progress is 
slower than might be considered desirable for clinicians wishing to put cutting-edge technology to clinical use.

\section{History of nanotechnology in dentistry}

In the last 10 years numerous theoretical predictions have been made based on the potential applications for nanotechnology in dentistry, with varying levels of optimism..$^{13,14}$ In 2000, Freitas echoed the 1959 prediction in the popular lecture by the late physicist Richard P Feynman (who won the Nobel prize for physics in 1965). This prediction accompanied the birth of nanotechnology's definition and vision: that the atomic-level precision afforded by molecular devices operating at the nanoscale was an inevitable technologic eventuality. ${ }^{13}$ Ironically, Feynman himself referred to the year 2000 in this same lecture, predicting a retrospective incredulity that serious focus on nanotechnology did not happen until 1960. ${ }^{15}$ The theme of anticipated versus realized transition of emerging technology to actual practice is not new. ${ }^{16}$ The pace of its applications to dentistry has been less than revolutionary. Even so, nanotechnology's impact on dental education has captured the interest of academicians, who are assessing its impact on dental curricula. ${ }^{17}$

This article will address the current major representation of practical nanotechnology in dentistry: restoration of tooth structure with RBCs that make use of nanoparticles. In addition, it will summarize dental biomimetic research contexts. Specifically, it will examine nanoscale processes currently being studied in dental research laboratories that bear striking resemblances to natural processes such as dental enamel formation.

\section{Overview of nanostructures for dental applications Nanoparticles}

Nanoparticles (molecular units typically defined as having diameters of between 0.1 and $100 \mathrm{~nm}$ ) of various composition represent the most widespread use of nanoscale units in dentistry. They are currently being used in RBC restorations; two-year clinical results have been published for several of them and will be discussed. ${ }^{18-21}$

Together with the evolution of nanoparticles for dental composites, sharper focus is being applied to reformulations of interfacial silanes. These have been used for many years to coat and bond inorganic fillers into RBC matrices in dental restoratives. Considerable research related to nanocomposites is focusing on tailoring newer types of silane bonding agents for optimal use with nanoparticles in RBCs. Organosilanes such as allyltriethoxysilane have demonstrated good compatibility with nanoparticle fillers such as $\mathrm{TiO}_{2}{ }^{22}$ In addition, 3-methacryloxypropyltrimethoxysilane has also been demonstrated to enhance dispersion of silica nanoparticles (5-25 nm) within the restorative resin matrix. ${ }^{23}$

Silanization has been reported by Chan and colleagues ${ }^{24}$ as one of several theoretical avenues for increasing fracture toughness of nanocomposites. $\mathrm{Xu}$ and colleagues also reported that silanization increased the strength of a novel ion-releasing calcium phosphate $\left(\mathrm{CaPO}_{4}\right)$ composite, but decreased the level of release. ${ }^{25}$ Another study by Karabela and Sideridou also found that different silane compositions used to bind composites containing silica nanoparticles had different effects on sorption of organic solvents and water by the RBC, as well as solubility of the RBC. ${ }^{26}$ Nanoparticles and associated modifications of existing RBC systems have a considerable record of demonstrated clinical utility and widespread use. Nanohybrid RBCs are currently the most ubiquitous example of such technology.

\section{Nanorods}

Nanorods are of particular interest in a restorative context. Chen and colleagues have synthesized enamel-prism-like hydroxyapatite (HA) nanorods that have exhibited selfassembly properties. ${ }^{10}$ Since they are similar to the enamel rods that make up the basic crystalline structure of dental enamel, nanorods could contribute to a practical artificial approximation of such a naturally-occurring structure.

\section{Nanospheres}

In a similar direction, such a potential transition to restorative systems that also mimic nanoscale processes already inherent in natural tooth development will also be explored in this article. Specifically, nanosphere assembly in conjunction with calcium phosphate deposition and amelogenin nanochain assembly will be discussed in a restorative context. ${ }^{12}$

\section{Nanotubes}

Nanotubes of various types have been investigated for dental applications in a number of interesting directions. Titanium oxide nanotubes have been shown in vitro to accelerate the kinetics of HA formation, mainly in a context of bone-growth applications for dental implant coatings. ${ }^{27}$ More recently, modified single-walled carbon nanotubes (SWCNTs) have been shown to improve flexural strength of RBCs. These SWCNTs had silicon dioxide applied to them in conjunction with specialized organosilane bonding agents. ${ }^{28}$ 


\section{Nanofibers}

Nanofibers and their uses for biomedical applications have been reviewed..$^{29}$ More recently, nanofibers have been used to generate ceramics containing HA and fluor-HA. ${ }^{30}$ Nanofibrillar silicate crystals have also been recently studied in the capacity of reinforcement of dental composites, specifically a combination of the widely-used 2,2'-bis-[4-(methacryloxypropoxy)phenyl]-propane (Bis-GMA) with triethylene glycol dimethacrylate (TEGDMA) added as a thinning agent. ${ }^{31,32}$ Added in the correct proportions ${ }^{32}$ and with uniform distribution of the fibers/crystals, ${ }^{31}$ nanofibers were demonstrated to improve the physical properties of these composites.

\section{Dendrimers and dendritic copolymers}

Dendrimers and dendritic copolymers have been studied, albeit less extensively than other nanostructures, in relation to dental composite applications. Combinations of specific polymers to optimize efficacy of restorative applications have been reported. ${ }^{33-35}$

\section{Restorative dentistry using nanocomposites}

Evolution of direct RBC systems to the level of the nanofill composite has been recently reviewed by Puckett and colleagues. ${ }^{36}$ The materials' physical properties have improved considerably (especially over the past five years). These changes have occurred in response to the persistent and daunting issues of polymerization shrinkage, and the dependable strength, microhardness, and associated wear resistance required in posterior occlusal applications. The ongoing challenge remains one of continuing to meet the esthetic demands of patients and clinicians.

\section{Nanoparticles and microfills from the 1970s forward}

In the early 1970s, Johnson and Johnson (Langhorne, PA, USA) introduced the composite, Adaptic (which contained a resin matrix filled with ground quartz particles). This material was shortly followed by $3 \mathrm{M}$ 's composite, Concise $^{\mathrm{TM}}$ (3M ESPE, St. Paul, MN, USA). Both quickly gained wide acceptance as anterior restoratives. Their main drawback was the surface discoloration that resulted from the coarse quartz particles they contained. (Michl, pers comm) These materials have also been used extensively for crown core buildups for more than 25 years.

Since the beginning of the era of microfills in 1973 and their commercialization via the patent process in Germany
(Patentschrift DE 2403211 C3 filed January 1974) and the following year in the United States (US Patent 4,267,097 filed January 1975), RBCs have been increasingly used in place of amalgam as the filler-matrix technologies have improved.

Microfilled composites use silicon dioxide filler particles less than $100 \mathrm{~nm}$ in diameter in conjunction with prepolymerized organic fillers, aggregated by crushing them into larger filler particles. While this system produces consistently high-quality surface smoothness and has the longest clinical track record, these restorations lack the high strength needed to emulate amalgam. ${ }^{37}$

During this same period in which microfills were gaining popularity, nanomaterials were already available as titanium dioxide, aluminum oxide and silica oxide. These were used in dental products in small amounts $(1 \%-5 \%)$ to improve powder flow. One of the nanosilica oxide products previously manufactured by Degussa in Germany (currently Dentsply International, York, PA, USA) was silanized with a methyl silan (Ox-50). This led to research attempts to fill the resin matrix with as much of the nanoparticle phase as possible, which resulted in the development of the restorative materials Isopast $^{\circledR}$ and Heliomolar ${ }^{\circledR}$ by Ivoclar Vivadent (Schaan, Liechtenstein). This novel development was quickly emulated by $3 \mathrm{M}$ ESPE (Michl, pers comm).

The progressive development of RBCs to date, including microfilled and nanofilled restoratives, has been recently reviewed by Christensen. ${ }^{37}$ Microfilled composites have the longest clinical track record, and provide a consistently smooth surface. However, microfills' lack of strength necessary for Class-I and -II occlusal applications has been a primary driver of the ongoing debate about progressive RBC use in applications typically - or perhaps traditionally - served by amalgam. The most commonly used RBCs currently comprise microhybrids and nanohybrids (virtually interchangeable terms). These materials use filler particles ranging from $<100 \mathrm{~nm}$ to $600+\mathrm{nm}$ and have overcome most of the strength issue. Nanofills (such as Filtek ${ }^{\mathrm{TM}}$ Supreme Plus [3M ESPE] and Estelite ${ }^{\circledR}$ Sigma [Tokuyama America, Inc., Encinitas, CA, USA]) offer the combined advantage of less surface roughness than nanohybrids, with smoothness that approximates that of microfills, albeit with a much shorter clinical track record. ${ }^{37}$

Overall performance of RBCs for posterior applications has improved over the past two decades as systems have evolved to the use of nanofillers. ${ }^{36}$ This has happened in parallel with a progressive decrease in filler-particle size, from a range of $<100-600^{+} \mathrm{nm}$ for nanohybrids and microhybrids to consistently less than $100 \mathrm{~nm}$ for nanofills and 
microfills. ${ }^{37}$ Nanocluster particles as small as $2-20 \mathrm{~nm}$ are currently being used as nanofilled restoratives. ${ }^{38} \mathrm{~A}$ practical aim of this "paring down" of particle size to the nanoscale has been described by Mitra and colleagues in terms of critical length scale, a limit that applies to every physical property. By creating particles smaller than this limit, a material's desirable performance (eg, optical properties, with a potential bearing on esthetics) can be maximized. ${ }^{38}$

\section{Top-down versus bottom-up manufacturing approach}

Nanotechnology has redefined the focus on how newer and smaller materials are created. Traditional manufacture of filler particles for dental composites has required the comminution of larger particles of quartz, glass, or ceramics through grinding or milling. Since this process cannot effectively produce particles less than approximately $100 \mathrm{~nm}$ in diameter, direct molecular assembly, or "bottom-up" processes that involve synthetic chemical processes must be used. ${ }^{38}$

\section{Physical properties of nanocomposites and rationale for their advantages}

Nanohybrid and nanofilled RBCs are generally the two types of composite restorative materials referred to under the term "nanocomposite", usually in a context of particle size. ${ }^{16,39}$ These are usually distinguished from their predecessors, microhybrids and the older conventional microfilled RBCs, mainly in terms of particle size combinations and distributions, which can vary greatly. Mean individual particle size of the older composites has exceeded $1 \mu \mathrm{m}$, and experimental filler analyses in relation to physical properties of dental RBCs have involved filler particles as large as $15.5 \mu \mathrm{m} .{ }^{40}$ Comparative in vitro studies evaluating physical properties of the various types of RBCs are summarized in Table 1.

Nanohybrid composites possess a wider range of particle sizes, and multiple filler compositions. For example, inorganic particles averaging $7 \mathrm{~nm}$ together with larger glass particles averaging $<2000 \mathrm{~nm}$ are used in NANOSITTM nanohybrid composite (Nordiska Dental, Angelholm, Sweden) ${ }^{41}$ Nanofills have a more uniform particle size range $(\mathrm{eg}, 75 \mathrm{~nm}$ and 5-20 nm for translucent and nontranslucent shades of Filtek $^{\mathrm{TM}}$ Supreme Plus [3M ESPE], respectively). ${ }^{42}$

The use of combinations of nanomeric particles and nanoclusters was introduced with Filtek ${ }^{\mathrm{TM}}$ Supreme (3M ESPE). The intent was to promote better wear patterns by using nanosized primary particles (between 2 and $75 \mathrm{~nm}$, depending on the shade) breaking off from the bottom-up designed larger clusters $(0.6-1.4 \mu \mathrm{m})$. This would result in a smoother surface than would breakage of the much larger, nonsubdividable particles (produced via top-down manufacturing) contained in many hybrids. ${ }^{38}$

Materials with this cluster structuring have been reported to have distinct mechanical and physical properties compared with conventional RBCs, including better maintenance of biaxial flexural strength during six months of water immersion, in contrast to a microhybrid tested. ${ }^{43}$

Another study by Turssi and colleagues ${ }^{44}$ found considerable variation among different nanocomposites in a threebody wear test conducted in an oral wear simulator, as well as flexural fatigue limit (FFL) analysis by the staircase method. Of these materials, a microfill control (Heliomolar ${ }^{\circledR}$; Ivoclar Vivadent), a nanohybrid (Grandio ${ }^{\circledR}$; Voco GmbH, Cuxhaven, Germany) and an agglomerated cluster/fine-particle nanofill (Filtek ${ }^{\mathrm{TM}}$ Supreme) showed significantly higher FFL than either an ormocer-based RBC (Ceram $\mathrm{X}^{\mathrm{TM}}$ mono; Dentsply International, York, PA, USA), or another nanohybrid (Premise ${ }^{\mathrm{TM}}$; Kerr Corp., Orange, CA, USA). Ormocers are discussed below in greater detail.

The rationale for broader particle-size range of hybrids includes manufacturer statements of superior esthetics, surface and polishability. ${ }^{41,45}$ While comparisons with older materials may prove the hypothesis, comparisons with nanofills tend to show that their esthetics are at least noninferior to those of nanohybrids. A comparative study by Yap and colleagues demonstrated that materials based on ormocer and nanomer technology were significantly smoother than those based on microfillers and nanoclusters. These composite materials, in turn, were significantly smoother than glass ionomers and compomers. For the material group that was finished and polished (as opposed to the group that received polymerization against a matrix strip only), roughness values observed for the ormocer and nanofill were significantly lower than those observed for the microfill and nanocluster composites. ${ }^{46}$

The ongoing hypothesis for the use of progressively decreasing filler particle sizes is a model of better dispersion and increased interfacial area between matrix and filler. This should translate into increased flexural strength, surface microhardness, and thus polishability of the finished restoration.

Tanimoto and colleagues published a computational approach that quantified an observed progressive decrease in flexural strength as the mean filler-particle diameter increased. This investigation was limited to silica fillers ranging from 3.3 to $15.5 \mu \mathrm{m},{ }^{40}$ which is considerably above the maximum particle size range of nanohybrids or nanofills. 
However, a study by Beun and colleagues ${ }^{47}$ compared the physical properties of nanofilled, universal hybrid and microfilled composites, and observed a higher elastic modulus with the nanofilled RBC than most of the hybrids tested. While all materials tested exhibited similar flexural strengths, microfills showed the poorest physical properties overall.

Glass-ionomer cements have been reported to have significantly poorer surface-finish and esthetic properties than the newer composites. ${ }^{46}$ However, manufacturers have begun to incorporate nanoscale structuring to produce "nanoionomers," in an effort to make their surface finish more closely approximate that of a hybrid composite. One recent in vitro study by Oxman and colleagues compared Ketac ${ }^{\mathrm{TM}}$ Nano (3M ESPE), a paste/paste nanoionomeric hybrid resin-modified glass ionomer (NHRMGI) with two fluoroalumiosilicate RMGIs (Fuji II LC and Fuji Filling LC [GC America, Inc., Alsip, IL USA]) and a nanohybrid composite (Tetric EvoCeram ${ }^{\circledR}$ ) by ANOVA with Tukey's comparison at $P<0.05$. Ketac ${ }^{\mathrm{TM}}$ Nano showed significantly higher gloss than the other RMGIs (initial polish numbers by gloss meter were $36.5 \pm 1.3$ versus $64.2 \pm 11.1$ for Tetric EvoCeram), with greater similarity to that of a hybrid composite (three-body wear depth at 80,000 cycles of $21.8 \pm 1.3 \mu \mathrm{m}$ versus $6.8 \pm 0.4 \mu \mathrm{m}$ for Tetric EvoCeram $^{\circledR}$ ). Wear rates for the other RMGIs were significantly higher than for Ketac $\mathrm{Nano}^{\circledR} .{ }^{.48}$

\section{Ormocers}

Ormocer ${ }^{\circledR}$ is an acronym for organically modified ceramics, a registered trademark of Fraunhofer-Gesellschaft (Munich, Germany). Ormocers represent a new technology based on sol-gel synthesis using particles comprising silicones, organic polymers, and ceramic glasses that is applicable to dental composites. ${ }^{49}$ Ormocer $^{\circledR}$ composite technology is used in conjunction with nanoparticle fillers such as $\mathrm{ZrO}_{2}$ that are widely used in nanocomposite restorative systems. Some ormocers (such as Ceram $\mathrm{X}^{\mathrm{TM}}$ [Dentsply International]) contain particles as small as $2-3 \mathrm{~nm}$ in diameter. ${ }^{50}$

Modifying ormocers with organic moieties such as methacrylate-substituted $\mathrm{ZrO}_{2}$ or $\mathrm{SiO}_{2}$ organosol nanoparticles was found by Moszner and colleagues to improve the mechanical properties of RBCs. ${ }^{51}$ This study also describes ormocers as being more biocompatible, ${ }^{51}$ a claim echoed by one manufacturer (Voco GmBh).$^{52}$ Ormocers also claim decreased surface roughness, which is supported by in vitro evidence involving a variety of polishing techniques (see Table 1). ${ }^{46,53}$

An in vitro study by Montanaro and colleagues examined the adhesion of Streptococcus mutans strain ATCC 25175 to the ormocer ${ }^{\circledR}$ Admira (Voco GmBh), glass ionomers including Fuji IXFAST (GC Amercia), a compomer, flowable composites, and microhybrids. Admira and Fuji IX ${ }^{\mathrm{TM}}$ FAST were more susceptible to $S$. mutans adhesion than a polystyrene control. The other materials showed adhesion similar to the control. ${ }^{54} \mathrm{Clinical}$ evaluations of ormocer-based composites compared with nanofills are discussed below.

\section{Esthetics of nanocomposites}

An early goal of nanocomposite development was the introduction of materials that possessed the strength to function under the stresses of Class I and Class II occlusal applications, while at least replicating the esthetic standards of hybrids and microfills. With this objective, Mitra and colleagues used bottom-up manufacturing design to produce a nanocomposite that contained a combination of nanomericparticle and nanocluster nanofillers that possessed physical properties comparable to hybrids and with esthetic properties comparable to microfills. ${ }^{38}$ This formulation is currently used in Filtek ${ }^{\mathrm{TM}}$ SupremePlus nanocomposite (3M ESPE).

Nanocomposites have been reported for the past several years to offer desirable overall esthetics, function and biocompatibility for anterior restorations. A two-part series published in 2004 by Terry ${ }^{55,56}$ provided initial clinical recognition of nanocomposites' role in the esthetic dentist's armamentarium. The series recaps the history of nanocomposite development and provides clinical guidance specifically for their use in anterior restorations. ${ }^{55} \mathrm{~A}$ case report by Milnar also illustrates predictable replication of esthetics via combined use of a direct nanofill and calorimetric analysis for shade selection. ${ }^{57}$ A study by Beun and colleagues that primarily highlights the elastic strength of nanofills comments on their esthetic utility in anterior restorations as well. ${ }^{47}$ Favorable compatibility of nanofills with esthetic dentistry has also been reported by Ward. ${ }^{58}$ However, larger-scale clinical colorimetric esthetic studies comparing nanocomposites with older-generation $\mathrm{RBCs}$ are lacking to date.

Significant improvement in surface smoothness/polish retention have been reported for nanofills compared with conventional microfills. ${ }^{59,60}$ Yap and colleagues reported that a nanomer-based RBC (Filtek ${ }^{\mathrm{TM}}$ Supreme Translucent) as significantly smoother than nanocluster-based RBCs (Filtek ${ }^{\mathrm{TM}}$ Supreme [dentin]) ${ }^{46}$ This is an interesting observation in view of a more recent study by Senawongse and Pongprueksa, in which the same nanocluster RBC system produced the smoothest overall finish after polishing or brushing, measured by both scanning electron microscope (SEM) and surface roughness tester. ${ }^{61}$ 


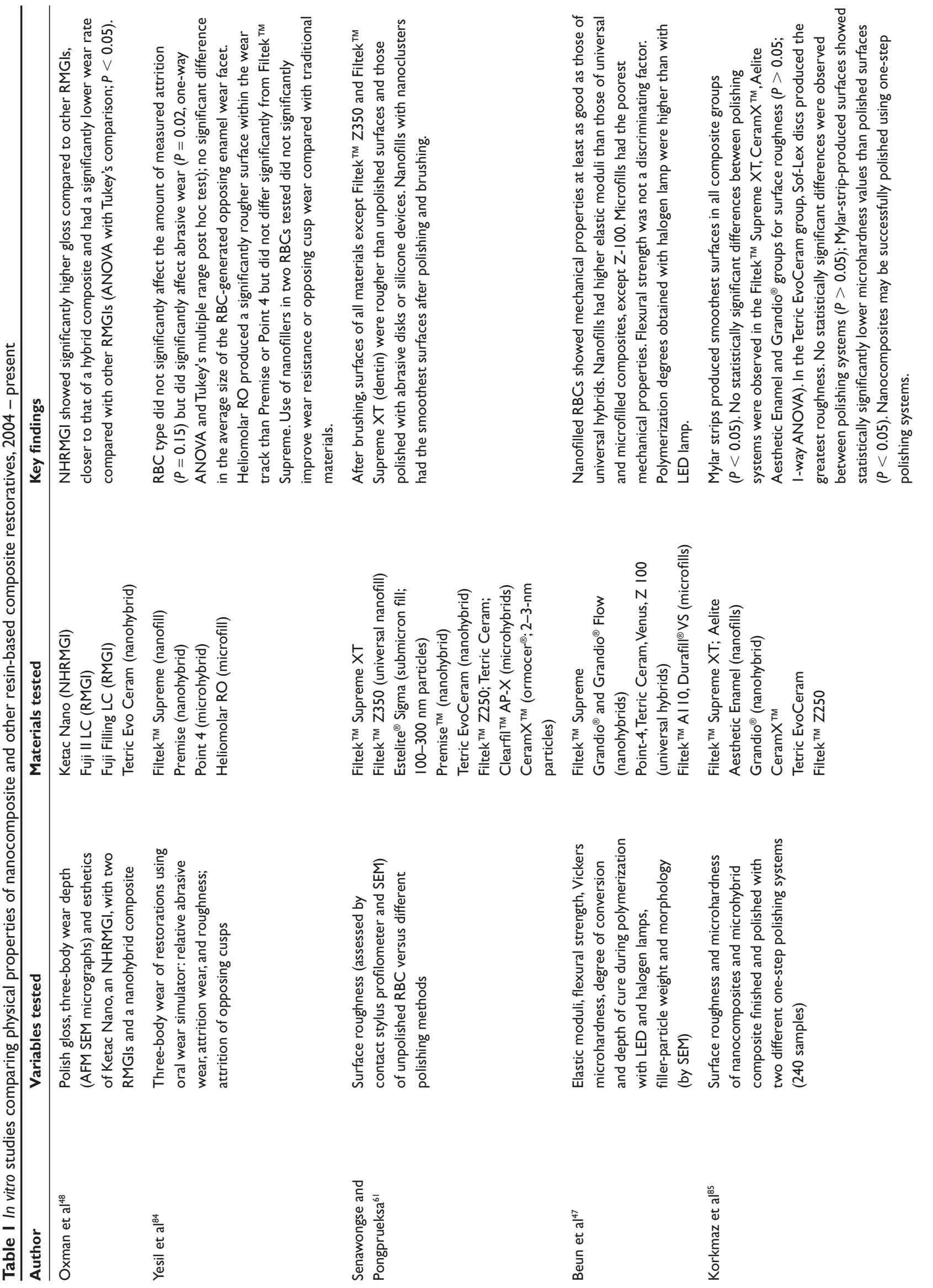



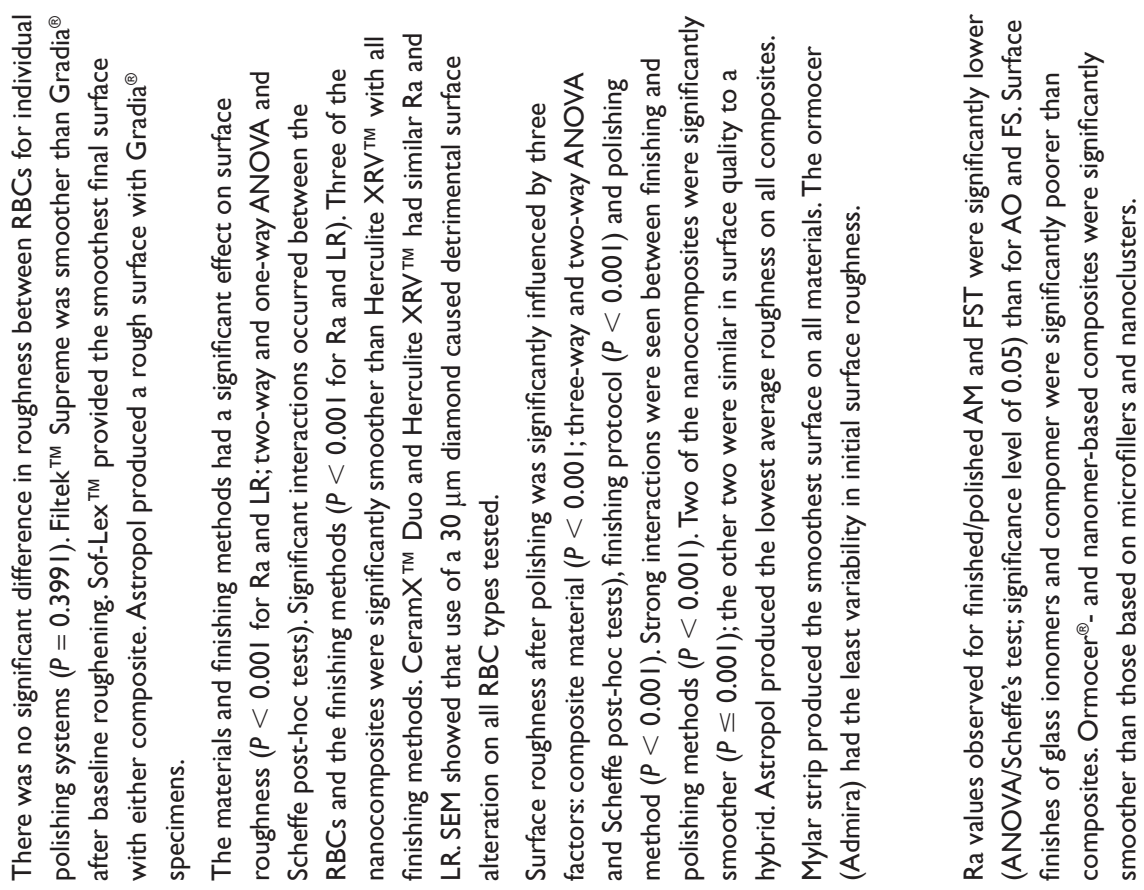

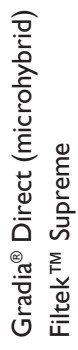

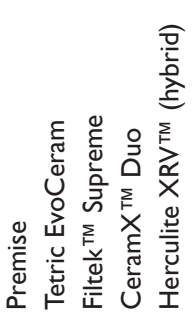

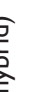
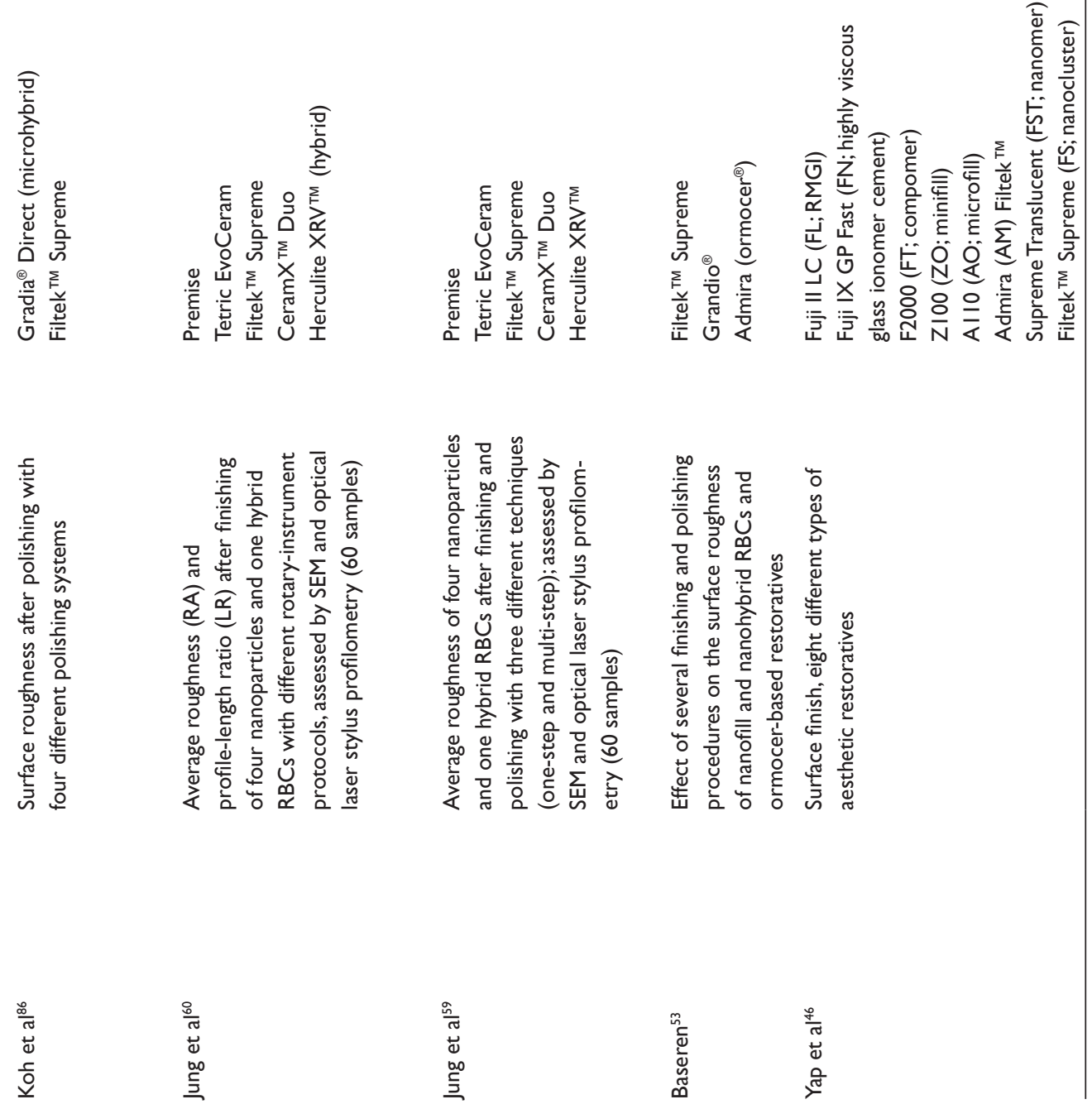
Additional comparative studies show that the physical properties of nanocomposites are comparable to or better than those of the later-generation microhybrids, ${ }^{43,62}$ including a two-year clinical assessment by Ernst and colleagues that compared a nanofilled RBC with a fine-particle hybrid and showed similar performance. ${ }^{19}$ Studies of this type are perhaps the best initial clinical predictor of nanocomposites' evolving track record.

\section{Clinical studies: the first two years of nanocomposite performance data}

Terry's early review of the evolution of the nanocomposite in 2004 made assessments regarding increased strength, durability and longevity of nanocomposites..$^{56}$ To date, the predominant trends in studies comparing two-year data for the various gradations of nanocomposites to those of conventional composites have shown clinical acceptability and noninferiority, but probably not a clearly revolutionary advantage in terms of actual clinical performance, at least not at the current time point.

Several clinical studies published in the last three years have begun to benchmark the clinical record of nanocomposites. Results across these studies are similar and consistent, which is a positive sign for the clinician making greater use of nanocomposites in restorative practice. Similarly, a comprehensive summary of such similar results is important from a benchmarking perspective. Retrospective evaluation may identify nuances in study design that have a bearing on the continued evolution and specific utility of such restoratives.

As stated above, Ernst and colleagues ${ }^{19}$ compared the nanofill Filtek ${ }^{\mathrm{TM}}$ Supreme with a conventional fine hybrid (Tetric Ceram, Ivoclar Vivadent) in Class-II applications. Each of 50 patients received one restoration with each material in a split-mouth design. After two years there was no statistically significant difference in durability between the two materials as measured by Ryge criteria. A summary of studies involving the longest-term clinical evaluations to date for nanocomposite performance is presented in Table 2 .

Eighteen-month results of a clinical study comparing the nanofill Filtek ${ }^{\mathrm{TM}}$ Supreme (3M ESPE) with the nanohybrid Grandio $^{\circledR}$ (Voco $\mathrm{GmbH}$ ) to restore carious lesions in combination with an antibacterial adhesive by Ergucu and Turkun ${ }^{63}$ were also favorable. The only statistically significant difference was greater surface roughness with Grandio ${ }^{\circledR}$ than with Filtek ${ }^{\mathrm{TM}}$ Supreme $(P<0.05$, see Table 2$)$.

Additional clinical studies reporting two-year data for performance of nanofills, nanohybrids, and ormocers compared with conventional microhybrid RBCs used in occlusal restorations have been published by Mahmoud and colleagues $^{64}$ and Efes and colleagues. ${ }^{18,65}$

Mahmoud and colleagues analyzed 140 restorations (Admira [Voco GmbH] an ormocer ${ }^{\circledR}$ RBC; Tetric EvoCeram ${ }^{\circledR}$, a nanohybrid; Filtek ${ }^{\mathrm{TM}}$ Supreme, a nanofill; Tetric $\mathrm{Ceram}^{\circledR}$, a microhybrid RBC) in 35 patients, each of whom received 1 restoration of each type. After two years, all three types of the newer composites performed similarly to the microhybrid RBC tested, with no statistically significant difference $(P>0.05)$ in United States Public Health Service (USPHS) modified Ryge scoring criteria. ${ }^{64}$

Efes and colleagues compared two types of newer RBCs: the ormocer ${ }^{\circledR}$ Admira and the nanofill Filtek ${ }^{\mathrm{TM}}$ Supreme with Renew (a conventional hybrid). Over a two-year period, they evaluated 90 Class-I maxillary restorations in 90 patients, with specific endpoints of hypersensitivity and secondary caries. Except for one ormocer ${ }^{\circledR}$ restoration, which had failed at two years, no secondary caries or hypersensitivity was evident for any RBC tested $(P>0.05)$. All materials' performance was clinically acceptable (see Table 2 ) ${ }^{65}$ An additional study by Efes and colleagues also showed excellent two-year performance by the same nanofill and ormocer ${ }^{\circledR}$. Two previously calibrated dentists evaluated the two restoratives using the same criteria with regard to secondary caries, marginal adaptation, surface texture and other variables. This study also evaluated the use of a flowable liner with each of these materials; it offered no additional benefit for either one. ${ }^{18}$

Finally, Schirrmeister and colleagues ${ }^{21}$ compared the ormocer RBC CeramX $\mathrm{X}^{\mathrm{TM}}$ with the microhybrid TetricCeram, with a potentially confounding variable of the use of K-0127 primer/adhesive for both RBCs; 31 of 43 patients (each of whom had received one Class-I or Class-II molar restoration with each $\mathrm{RBC}$ ) returned for the two-year recall visit. One Ceram $X^{\mathrm{TM}}$ restoration had failed (removal was necessary due to pulpitis and need for root canal treatment). While some marginal discoloration was noted for both RBCs, no statistically significant changes were noted for surface texture, and no sensitivity or recurrent caries occurred $(P>0.05) .{ }^{21}$

In summary, the comparative clinical performance to date among the various types of nanocomposites as well as in comparison with older hybrids does not yet show a clear advantage for nanofills. Continued systematic benchmarking of longevity and clinical acceptability data from this type of comparative study are essential for any such advantage to be noted as RBCs continue to evolve. Nevertheless, consistent clinical acceptability and low failure rates evident from these studies are encouraging. 


\section{In vitro nanotechnologic dental research approaching clinical feasibility Nanofibrillar reinforcement}

Two recent in vitro studies by Tian and colleagues ${ }^{31,32}$ have provided interesting insights based on the theme of nanofibers and nanocrystals. Nanofibrillar silicate crystals can be used either alone ${ }^{31}$ or in conjunction with nanofibers, to reinforce bis-GMA/TEGDMA-based nanocomposites. ${ }^{32}$ Both studies found that the addition of such nanostructures in smaller amounts up to an effective threshold improved mechanical properties of the experimental RBC.

\section{Caries prevention}

Optimal delivery of molecules that facilitate tooth structure remineralization and forestall caries is an active area of nanostructure-based research. Much of this work involves nanoparticles in conjunction with RBC systems.

$\mathrm{Xu}$ and colleagues recently published in vitro data on a stress-bearing, fluoride (F)-releasing nanocomposite whose flexural strength $(110 \pm 11 \mathrm{MPa})$ matched that of a commercial non-F-releasing RBC $(108 \pm 19 \mathrm{MPa})$. This material contains novel $\mathrm{CaF}_{2}$ nanoparticles in a whisker-reinforced resin matrix, and had sustained F-release values exceeding those of conventional and resin-modified glass ionomers. This study's results are summarized in Table 3. Such an RBC could offer the previously unavailable combination of the strength of a hybrid, and the F-releasing capacity of an RMGI that by itself is not suitable for high-stress occlusal restorations. ${ }^{66}$ Whisker reinforcement of RBCs has been known for some time to offer reduced brittleness and increased fracture toughness compared with conventional composites. ${ }^{67}$ Its use with nanoparticles as in the study described above could reduce rates of restoration fracture and secondary caries (see Table 3).

In a similar direction, several other recent studies by $\mathrm{Xu}$ and colleagues ${ }^{25,68,69}$ have evaluated the incorporation of nanosized $\mathrm{CaPO}_{4}$ particles into RBCs, with a resulting improvement in stress-bearing capacity as well as ion release that could inhibit caries. ${ }^{68}$ Further investigation of this model using dicalcium phosphate anhydrous (DCPA) incorporated with nanosilica-fused whiskers found that it increased the strength of the RBC by as much as threefold while releasing $\mathrm{CaPO}_{4}$. This release was greater with decreasing $\mathrm{CaPO}_{4}$ particle size. ${ }^{25}$ The authors hypothesize that such a system could provide a desirable combination of caries prevention and increased restoration strength. ${ }^{25,69}$ Lee and colleagues found a similar trend with reducing the particle size of a zirconia-amorphous calcium phosphate RBC filler, ie, good release properties were observed in addition to an increase in biaxial flexural strength. ${ }^{70}$ Finally, HA and fluorapatite bioceramic nanoscale fibers have been studied, with the interesting finding that nanostructure solubility could be manipulated to produce effective release of fluorine ions from fluorhydroxyapatite. ${ }^{30}$ When envisioned as part of a nanocomposite restorative or sealant system, such a process could have important applications in caries prevention.

\section{Biomimetics: amelogenins, hydroxyapatite, enamel replication and repair}

Perhaps the most tempting venue for speculation on the next phase of nanorestoration of tooth structure is that of nanotechnology mimicking processes that occur in nature (biomimetics), such as the formation of dental enamel. Salient research over the last six years on the theme of studying and replicating enamel formation is summarized in Table 3.

The central theme in the study of ways to mimic nature's already-efficient use of nanotechnology surrounds the cooperative interaction between self-assembled nanospheres of the proline-rich protein amelogenin (the most abundant protein in dental enamel), and the formation and directional orientation of HA crystals that compose enamel's hard-tissue mineral phase. Spanning a period between publication of earlier work by Fincham and Moradian-Oldak ${ }^{71,72}$ and Fincham and colleagues ${ }^{73,74}$ from the early 1990 s to the present, studies of various types of amelogenins continue to elucidate this protein's cooperational versatility among processes that occur at the nanoscale during the formation of dental enamel. ${ }^{75,76}$

A recent in vitro study by Wang and colleagues has further elucidated mechanisms of interaction among amelogenin nanospheres, nanoparticles and nanorods at critical points during the HA crystal-growth process. The results offer further evidence for cooperativity in interfacial matching between organic and inorganic nanophases that may resemble processes that occur in actual enamel formation. ${ }^{77}$ In another attempt to mimic enamel formation, Uskokovic' and colleagues also recently described such a synergy among protein self-assembly, proteolysis (through a pivotal role of matrix metalloprotease-20 [MMP-20], also known as enamelysin) and crystallization. They used an in vitro model with full-length human amelogenin (rH174) in a saturated aqueous calcium solution. ${ }^{78}$ Tarasevich and colleagues have described 





a process of disassembly or "shedding" of a variety of smaller substructures from nanospheres onto various organic and inorganic substrates, including those with methyl- and carboxylgroup functionality as well as crystal fluoroapatite. The authors hypothesize that amelogenin may have different functional and surface-interactive specificities. ${ }^{79,80}$ The emergence of an amelogenin-interactive role in macromolecular self-assembly and enamel mineralization for a second protein, enamelin, also has been reported recently by Fan and colleagues. ${ }^{81}$

A study of rat enamel organ by Brookes and colleagues suggests that nanospheres formed in vivo (through interaction with amelogenin) appear to be a basic assembly unit of enamel formation. Secretion and assembly of monomeric subunits likely results in mature nanospheres that contain full-length amelogenins. ${ }^{9}$ Hence, nanosphere assembly probably occurs intracellularly as a precursor to secretion of the enamel matrix. Self-assembly of synthesized and modified nanorods into an enamel prism-like structure has also been successfully done for human and rat enamel by Chen and colleagues. ${ }^{10}$ Regularity of amelogenin nanosphere assembly into microribbons was also observed by Du and colleagues, who hypothesized amelogenin's pivotal role in directing and ordering apatite crystal growth. ${ }^{11}$

Thus, pivotal roles for various nanostructure types appear inherent in dental enamel formation in nature. These lines of research suggest that such modes of assembly in nature are not dissimilar to the artificial assembly of nanostructures. The next logical step in this process would be successful emulation of "nature's use of nanotechnology" to develop a restorative that could be delivered practically as a toothstructure replacement.

Other recent studies by Fan and colleagues show perhaps the greatest advancement in this direction. One describes the development of an amelogenin-apatite composite. ${ }^{12}$ produced by electrolytic deposition of calcium phosphate simultaneously with the self-assembly of amelogenin nanochain structures, using a full-length recombinant amelogenin (rP172). Induction of parallel bundles of calcium phosphate nanocrystals was also evident. The authors noted that use of the full-length amelogenin (as compared with a truncated one) was critical to the optimal self-assembly of the apatite composite. The strength of the resulting composite was also dependent on use of the full-length amelogenin. They hypothesize that the organized-bundle morphology of such an amelogenin-assembled composite has important potential for its use as a restorative.

Fan and colleagues also found that dose-dependent enamel remineralization (via HA crystal growth) occurred 
Table 3 In vitro studies with relevance to caries prevention and the development of enamel/dentin restoratives involving biomimetic processes and nanostructures

\begin{tabular}{ll}
\hline Author & Material/process tested \\
\hline Xu et al ${ }^{66}$ & $\begin{array}{l}\text { Fluoride-releasing, stress-bearing nanocomposite } \\
\text { containing novel } \mathrm{CaF}_{2} \text { nanoparticles in a } \\
\text { whisker-reinforced dental resin }\end{array}$ \\
& \\
Zhou et al ${ }^{89}$ & $\begin{array}{l}\text { Synthesis and antibacterial activity of a } \\
\text { nanohydroxyapatite (n-HA)/zinc oxide }(\mathrm{ZnO}) \\
\text { complex }\end{array}$
\end{tabular}

Zhou et al ${ }^{83} \quad$ Genetically engineered peptides for inorganics (GEPIs)

Fan et al ${ }^{82}$

Fan et al ${ }^{12}$

Brookes et al ${ }^{9}$

Du et al"

Beniash et $\mathrm{al}^{90}$

Bouropoulos and Moradian-Oldak ${ }^{91}$
Clarificaction of the role of amelogenin (the most abundant protein in dental enamel) in enamel mineralization

Amelogenin (recombinant rPI72 at concentrations above or below $33 \mu \mathrm{g} / \mathrm{mL}$ ) used with a modified biomimetic deposition method in the presence of fluoride to remineralize etched enamel

Preparation of a material mimicking developing enamel (comprising calcium phosphate mineral, water, and enamel matrix proteins, mainly amelogenins); simultaneous assembly of amelogenin and calcium phosphate precipitates by electrolytic deposition

Investigation of specific intracellular/secretory processes/locations of in vivo assembly of amelogenin nanospheres using rat enamel organs using a bifunctional cross-linker, dithio bis succinimidyl propionate and gel electrophoresis/ western-blot probing

In-vitro formation of birefringent microribbon structures that were generated through the supramolecular assembly of amelogenin

Investigation of interactions of recombinant mouse amelogenin nanospheres with hydroxyapatite crystals in solution using a Langmuir model of adsorption site specificity of amelogeninhydroxyapatite binding nanospheres

\section{Key findings}

Flexural strength (mean $\pm S D ; n=6$ ) was $110 \pm 11 \mathrm{MPa}$

for the composite containing $30 \% \mathrm{CaF}_{2}$ and $35 \%$ whiskers by mass (equivalent to $108 \pm 19 \mathrm{MPa}$ for stress-bearing, nonreleasing commercial composite; Tukey's at 0.05 ). The composite containing $20 \% \mathrm{CaF}_{2}$ had a cumulative $\mathrm{F}$ release of $2.34 \pm 0.26 \mathrm{mmol} / \mathrm{L}$ at 10 weeks. This formulation may reduce the occurrence of secondary caries and restoration fracture.

Two phases of $\mathrm{ZnO}$ and $\mathrm{n}$-HA combined closely; this complex possessed strong antibacterial capability ( $99.45 \%$ to Staphylcoccus aureus and $95.65 \%$ to Escherichia coli under light, respectively).

Since an ideal dental restorative would mimic natural tooth structure, an analog of dental hard tissue (ie, hybrid of GEPIs and hydroxyapatite crystals), might be engineered using the recognition properties between GEPIs and HA crystal. GEPIs can be used in the assembly of functional nanostructures.

At a concentration of $33 \mu \mathrm{g} / \mathrm{mL} \mathrm{rPI} 72$ and I $\mathrm{mg} / \mathrm{L}$ fluoride, amelogenin initiated oriented bundle formation of fused needle-like fluoridated hydroxyapatite crystals from enamel surface in a dose dependent manner. Restorative/reparative dental biomaterial could be developed using an amelogenin fluoridated hydroxyapatite nanocomposite.

Formation of organized bundles in amelogenin-apatite composites results from amelogenin nanochain assembly; such materials have potential applications as dental restorative materials.

Intracellular amelogenin monomers are in close neighbor contact, forming complexes comprising up to six individual amelogenin monomers; authors suggest that these initial complexes are prefabricated intracellularly before secretion; post-secretion the prefabricated subunits assemble into full-size nanospheres containing numerous individual amelogenins (as in enamel matrix).

Authors observed growth of apatite crystals orientated along $\mathrm{c}$-axis and parallel to long axes of the microribbons in vitro. Chains of self-assembled amelogenin nanospheres observed as intermediate states before microribbon formation suggest a key role for amelogenin in controlling the oriented apatite crystal growth during mineralization of enamel.

Amelogenin's larger hydrophobic portion is involved in inhibition of crystal growth. Importantly, its I 3-amino-acid hydrophilic C-terminal domain is essential for the alignment of crystals into parallel arrays, which only occurs with full-length monomeric amelogenin. Enamel is formed through cooperative interactions between forming crystals and assembling proteins.

Authors described a numerical relationship between number of amelogenin nanospheres and hydroxyapatite crystal surface area covered by each population of nanospheres at maximum adsorption. They hypothesized that amelogenin binding onto apatite surface is selective and probably occurs only at certain sites. 
under the direction of rP172 amelogenin (at a concentration of $33 \mu \mathrm{g} / \mathrm{mL}$ ) in the presence of fluoride (F) at a concentration of $1 \mathrm{mg} / \mathrm{L}$. These results further emphasize the pivotal implications of amelogenin F-HA nanocomposite development for the restorative setting. ${ }^{82}$

Finally, genetically engineered peptides for inorganics (GEPIs) have recently been hypothesized by Zhou and colleagues to have practical implications for tooth repair, if they can be engineered to recognize inorganic HA and form a hybrid with it (see Table 3). ${ }^{83}$

If some commercially viable combination of these processes could be developed into an amelogeninnanosphere-based, HA-replicating, F-releasing, enamelreplicating restorative, its clinical implications would be significant. A conservative estimate might still place commercial availability of such a restorative system one to two decades away. However, a progression of improving technology systems based on biomimetic use of nanostructured materials is not an unreasonable expectation.

\section{Conclusion}

Restorative dentistry relies on time-tested methods. Currently, nanotechnology has had its greatest impact on restorative dentistry by offering refinements to already clinically proven RBC systems.

Esthetic dentistry has from its inception attempted to recreate the natural appearance of tooth structure. So, perhaps if the clinician can envision tooth development as a longstanding natural process to be emulated by human technology, tooth-structure restoration becomes a continuum encompassing nature itself, rather than just the stepwise advancement of chemical and physical technology.

Esthetic intent (and incorporation of greater strength) has driven the use of RBCs for an expanding range of applications, and has met with increasing clinical acceptance over the past 30 years. Such acceptance has embraced nanotechnologic restorative techniques on a number of esthetic restorative fronts, including nanofilled RBCs and nanoionomers.

In parallel with this, research over the last 15 years has categorized many nanotechnologic processes inherent in the natural formation of tooth structure. The perspective of emulating nature's appearance revolutionized esthetic dentistry through to the present mainstream use of nano-RBCs. This same perspective could supply the impetus for introduction of HA-F-amelogenin nanochain restorative technology into mainstream dentistry. Made practical and durable (as RBCs gradually evolved to be), such nanorestorative biomaterials could very credibly be the next transformative clinical leap.
Using retrospect - or perhaps hindsight - this leap is at least comparable in magnitude to today's widespread use of nanohybrid and nanofilled RBCs, compared with composites in use three decades ago.

\section{Acknowledgments}

The author reports no financial disclosures or conflicts of interest in this work. The author would like to thank Gordon J Christensen, DDS, MSD, PhD of The Scottsdale Center for Dentistry, Scottsdale, AZ, USA; Rudolf J Michl, PhD of Chemichl AG Vaduz, Liechtenstein; and William K Deal, DMD of Bryn Mawr Dental Health Group, Inc., Bryn Mawr, PA USA, for their invaluable critical review of this article.

\section{References}

1. Borlongan CV, Masuda T, Walker TA, et al. Nanotechnology as an adjunct tool for transplanting engineered cells and tissues. Curr Mol Med. 2007;7(7):609-618.

2. Catledge SA, Fries MD, Vohra YK, Lacefield WR, Lemons JE, Woodard S, et al. Nanostructured ceramics for biomedical implants. J Nanosci Nanotechnol. 2002;2(3-4):293-312.

3. Dalby MJ, Gadegaard N, Curtis AS, Oreffo RO. Nanotopographical control of human osteoprogenitor differentiation. Curr Stem Cell Res Ther. 2007;2(2):129-138.

4. Pierstorff E, Ho D. Monitoring, diagnostic, and therapeutic technologies for nanoscale medicine. J Nanosci Nanotechnol. 2007;7(9): 2949-2968.

5. Maye MM, Nykypanchuk D, van der Lelie D, Gang O. A simple method for kinetic control of DNA-induced nanoparticle assembly. J Am Chem Soc. 2006;128(43):14020-14021.

6. Reuter A, Dittmer WU, Simmel FC. Kinetics of protein-release by an aptamer-based DNA nanodevice. Eur Phys J E Soft Matter. 2007; 22(1):33-40.

7. Saravana KR, Vijayalakshmi R. Nanotechnology in dentistry. Indian J Dent Res. 2006;17(2):62-65.

8. Stevenson KA, Muralidharan G, Maya L, Wells JC, Barhen J, Thundat T. Covalent attachment of gold nanoparticles to DNA templates. J Nanosci Nanotechnol. 2002;2(3-4):397-404.

9. Brookes SJ, Lyngstadaas SP, Robinson C, Shore RC, Kirkham J. Intracellular nanosphere subunit assembly as revealed by amelogenin molecular cross-linking studies. Eur J Oral Sci. 2006;114 Suppl 1: 280-284; discussion 285-286, 382.

10. Chen H, Clarkson BH, Sun K, Mansfield JF. Self-assembly of synthetic hydroxyapatite nanorods into an enamel prism-like structure. J Colloid Interface Sci. 2005;288(1):97-103.

11. Du C, Falini G, Fermani S, Abbott C, Moradian-Oldak J. Supramolecular assembly of amelogenin nanospheres into birefringent microribbons. Science. 2005;307(5714):1450-1454.

12. Fan Y, Sun Z, Wang R, Abbott C, Moradian-Oldak J. Enamel inspired nanocomposite fabrication through amelogenin supramolecular assembly. Biomaterials. 2007;28(19):3034-3042.

13. Freitas RA Jr. Nanodentistry. J Am Dent Assoc. 2000;131(11): 1559-1565.

14. Schleyer TL. Nanodentistry. Fact or fiction? J Am Dent Assoc. 2000; 131(11):1567-1568.

15. Feynman RP. There's Plenty of Room at the Bottom. An Invitation to Enter a New Field of Physics. 1960 [cited 2009 August 2; Transcript of article appearing in February 1960 issue of Engineering and Science]. Available from: http://www.zyvex.com/nanotech/feynman.html.

16. Ure D, Harris J. Nanotechnology in dentistry: reduction to practice. Dent Update. 2003;30(1):10-15. 
17. Ford P, Seymour G, Beeley JA, et al. Adapting to changes in molecular biosciences and technologies. Eur J Dent Educ. 2008;12 Suppl 1: 40-47.

18. Efes BG, Dorter C, Gomec Y, Koray F. Two-year clinical evaluation of ormocer and nanofill composite with and without a flowable liner. J Adhes Dent. 2006;8(2):119-126.

19. Ernst CP, Brandenbusch M, Meyer G, Canbek K, Gottschalk F, Willershausen B. Two-year clinical performance of a nanofiller vs a fine-particle hybrid resin composite. Clin Oral Investig. 2006; 10(2):119-125.

20. Rosin M, Schwahn C, Kordass B, Konschake C, Greese U, Teichmann D, et al. A multipractice clinical evaluation of an ORMOCER restorative - 2-year results. Quintessence Int. 2007;38(6):e306-e315.

21. Schirrmeister JF, Huber K, Hellwig E, Hahn P. Two-year evaluation of a new nano-ceramic restorative material. Clin Oral Investig. 2006; 10(3):181-186.

22. Xia Y, Zhang F, Xie H, Gu N. Nanoparticle-reinforced resin-based dental composites. J Dent. 2008;36(6):450-455.

23. Kim JW, Kim LU, Kim CK. Size control of silica nanoparticles and their surface treatment for fabrication of dental nanocomposites. Biomacromolecules. 2007;8(1):215-222.

24. Chan KS, Lee YD, Nicolella DP, Furman BR, Wellinghoff S, Rawls HR. Improving fracture toughness of dental nanocomposites by interface engineering and micromechanics. Eng Fract Mech. 2007; 74(12):1857-1871.

25. $\mathrm{Xu} \mathrm{HH}$, Weir MD, Sun L. Nanocomposites with Ca and PO4 release: effects of reinforcement, dicalcium phosphate particle size and silanization. Dent Mater. 2007;23(12):1482-1491.

26. Karabela MM, Sideridou ID. Effect of the structure of silane coupling agent on sorption characteristics of solvents by dental resinnanocomposites. Dent Mater. 2008;24(12):1631-1639.

27. Oh SH, Finones RR, Daraio C, Chen LH, Jin S. Growth of nano-scale hydroxyapatite using chemically treated titanium oxide nanotubes. Biomaterials. 2005;26(24):4938-4943.

28. Zhang F, Xia Y, Xu L, Gu N. Surface modification and microstructure of single-walled carbon nanotubes for dental resin-based composites. J Biomed Mater Res B Appl Biomater. 2008;86(1):90-97.

29. Zhang Y, Lim CT, Ramakrishna S, Huang ZM. Recent development of polymer nanofibers for biomedical and biotechnological applications. J Mater Sci Mater Med. 2005;16(10):933-946.

30. Kim HW, Kim HE. Nanofiber generation of hydroxyapatite and fluorhydroxyapatite bioceramics. J Biomed Mater Res B Appl Biomater. 2006;77(2):323-328.

31. Tian M, Gao Y, Liu Y, Liao Y, Hedin NE, Fong H. Fabrication and evaluation of Bis-GMA/TEGDMA dental resins/composites containing nano fibrillar silicate. Dent Mater. 2008;24(2):235-243.

32. Tian M, Gao Y, Liu Y, et al. Bis-GMA/TEGDMA dental composites reinforced with electrospun nylon 6 nanocomposite nanofibers containing highly aligned fibrillar silicate single crystals. Polymer (Guildf). 2007;48(9):2720-2728.

33. Viljanen EK, Langer S, Skrifvars M, Vallittu PK. Analysis of residual monomers in dendritic methacrylate copolymers and composites by HPLC and headspace-GC/MS. Dent Mater. 2006;22(9):845-851.

34. Viljanen EK, Skrifvars M, Vallittu PK. Dendrimer/methyl methacrylate co-polymers: residual methyl methacrylate and degree of conversion. J Biomater Sci Polym Ed. 2005;16(10):1219-1231.

35. Viljanen EK, Skrifvars M, Vallittu PK. Dendritic copolymers and particulate filler composites for dental applications: degree of conversion and thermal properties. Dent Mater. 2007;23(11):1420-1427.

36. Puckett AD, Fitchie JG, Kirk PC, Gamblin J. Direct composite restorative materials. Dent Clin North Am. 2007;51(3):659-675, vii.

37. Christensen GJ. Has amalgam been replaced? Previous and current weaknesses of resin-based composites (RBCs) and suggested solutions. Clinicians Report. 2009;2(7):1-3.

38. Mitra SB, Wu D, Holmes BN. An application of nanotechnology in advanced dental materials. J Am Dent Assoc. 2003;134(10):1382-1390.

39. Swift EJ. Nanocomposites. J Esthet Restor Dent. 2005;17(1):3-4.
40. Tanimoto Y, Kitagawa T, Aida M, Nishiyama N. Experimental and computational approach for evaluating the mechanical characteristics of dental composite resins with various filler sizes. Acta Biomater. 2006; 2(6):633-639.

41. NordiskaDental. NANOSIT - nano hybrid composite. 2008 [cited 200825 Nov]; Available from: http://www.nordiskadental.se/nanosit. aspx?page $=$ composite.

42. 3M-ESPE. Filtek ${ }^{\mathrm{TM}}$ Supreme Plus Universal Restorative System technical product profile. 2008.

43. Curtis AR, Shortall AC, Marquis PM, Palin WM. Water uptake and strength characteristics of a nanofilled resin-based composite. J Dent. 2008;36(3):186-193.

44. Turssi CP, Ferracane JL, Ferracane LL. Wear and fatigue behavior of nano-structured dental resin composites. J Biomed Mater Res B Appl Biomater. 2006;78(1):196-203.

45. Pentron Clinical Technologies L. Simile product brochure. 2008 [cited $200825 \mathrm{Nov}$; Available from: http://www.pentron.com/pentron/ ClinicalSubcategoryDetail.cfm?id=132\&cat=30.

46. Yap AU, Yap SH, Teo CK, Ng JJ. Comparison of surface finish of new aesthetic restorative materials. Oper Dent. 2004;29(1):100-104.

47. Beun S, Glorieux T, Devaux J, Vreven J, Leloup G. Characterization of nanofilled compared to universal and microfilled composites. Dent Mater. 2007;23(1):51-59.

48. Oxman JD, Falsafi A, Mitra S, Ton TT, Madsen VJ, Bui HT. Improved polish, wear-resistance and esthetics of a nanoiomer restorative material [abstract]. London, UK: Pan European Federation of the International Association for Dental Research; 2008.

49. Fraunhofer-Gesellschaft. Ormocer. 2008 [cited 200826 Nov 2008]; Available from: http://www.ormocer.de/EN/.

50. Dentsply. Restorative dentistry; composites and restoratives: CeramX ${ }^{\text {TM }} .2009$ [cited 2009 August 21]; Available from: http://www. dentsply.com/default.aspx?pageid=777.

51. Moszner N, Gianasmidis A, Klapdohr S, Fischer UK, Rheinberger V. Sol-gel materials 2. Light-curing dental composites based on ormocers of cross-linking alkoxysilane methacrylates and further nanocomponents. Dent Mater. 2008;24(6):851-856.

52. Voco. 2008 [cited 200826 Nov]; Available from: http://voco.com/ index_en.html.

53. Baseren M. Surface roughness of nanofill and nanohybrid composite resin and ormocer-based tooth-colored restorative materials after several finishing and polishing procedures. J Biomater Appl. 2004;19(2):121-134.

54. Montanaro L, Campoccia D, Rizzi S, et al. Evaluation of bacterial adhesion of Streptococcus mutans on dental restorative materials. Biomaterials. 2004;25(18):4457-4463.

55. Terry DA. Direct applications of a nanocomposite resin system: Part 2 - Procedures for anterior restorations. Pract Proced Aesthet Dent. 2004;16(9):677-684; quiz 686.

56. Terry DA. Direct applications of a nanocomposite resin system: Part 1 - The evolution of contemporary composite materials. Pract Proced Aesthet Dent. 2004;16(6):417-422.

57. Milnar FJ. Selecting nanotechnology-based composites using colorimetric and visual analysis for the restoration of anterior dentition: a case report. J Esthet Restor Dent. 2004;16(2):89-100; discussion 101.

58. Ward DH. Esthetic restoration of tooth structure using a nanofill composite system. Compend Contin Educ Dent. 2005;26(4):252, 254, 256-257.

59. Jung M, Eichelberger K, Klimek J. Surface geometry of four nanofiller and one hybrid composite after one-step and multiple-step polishing. Oper Dent. 2007;32(4):347-355.

60. Jung M, Sehr K, Klimek J. Surface texture of four nanofilled and one hybrid composite after finishing. Oper Dent. 2007;32(1):45-52.

61. Senawongse P, Pongprueksa P. Surface roughness of nanofill and nanohybrid resin composites after polishing and brushing. $J$ Esthet Restor Dent. 2007;19(5):265-273; discussion 274-265.

62. Rodrigues SA, Jr., Ferracane JL, Della Bona A. Flexural strength and Weibull analysis of a microhybrid and a nanofill composite evaluated by 3- and 4-point bending tests. Dent Mater. 2008;24(3):426-431. 
63. Ergucu Z, Turkun LS. Clinical performance of novel resin composites in posterior teeth: 18-month results. J Adhes Dent. 2007;9(2):209-216.

64. Mahmoud SH, El-Embaby AE, AbdAllah AM, Hamama HH. Two-year clinical evaluation of ormocer, nanohybrid and nanofill composite restorative systems in posterior teeth. J Adhes Dent. 2008;10(4): 315-322.

65. Efes BG, Dorter C, Gomec Y. Clinical evaluation of an ormocer, a nanofill composite and a hybrid composite at 2 years. Am J Dent. 2006; 19(4):236-240.

66. Xu HH, Moreau JL, Sun L, Chow LC. Strength and fluoride release characteristics of a calcium fluoride based dental nanocomposite. Biomaterials. 2008;29(32):4261-4267.

67. Xu HH, Quinn JB, Smith DT, Antonucci JM, Schumacher GE, Eichmiller FC. Dental resin composites containing silica-fused whiskers - effects of whisker-to-silica ratio on fracture toughness and indentation properties. Biomaterials. 2002;23(3):735-742.

68. Xu HH, Sun L, Weir MD, Takagi S, Chow LC, Hockey B. Effects of incorporating nanosized calcium phosphate particles on properties of whisker-reinforced dental composites. J Biomed Mater Res B Appl Biomater. 2007;81(1):116-125.

69. Xu HH, Weir MD, Sun L, Takagi S, Chow LC. Effects of calcium phosphate nanoparticles on Ca-PO4 composite. J Dent Res. 2007; 86(4):378-383.

70. Lee SY, Regnault WF, Antonucci JM, Skrtic D. Effect of particle size of an amorphous calcium phosphate filler on the mechanical strength and ion release of polymeric composites. J Biomed Mater Res B Appl Biomater. 2007;80(1):11-17.

71. Fincham AG, Moradian-Oldak J. Amelogenin post-translational modifications: carboxy-terminal processing and the phosphorylation of bovine and porcine "TRAP" and "LRAP" amelogenins. Biochem Biophys Res Commun. 1993;197(1):248-255.

72. Fincham AG, Moradian-Oldak J. Recent advances in amelogenin biochemistry. Connect Tissue Res. 1995;32(1-4):119-124.

73. Fincham AG, Moradian-Oldak J, Sarte PE. Mass-spectrographic analysis of a porcine amelogenin identifies a single phosphorylated locus. Calcif Tissue Int. 1994;55(5):398-400.

74. Fincham AG, Moradian-Oldak J, Simmer JP, et al. Self-assembly of a recombinant amelogenin protein generates supramolecular structures. J Struct Biol. 1994;112(2):103-109.

75. Moradian-Oldak J, Du C, Falini G. On the formation of amelogenin microribbons. Eur J Oral Sci. 2006; 114 Suppl 1:289-296; discussion 327-289, 382 .

76. Moradian-Oldak J, Goldberg M. Amelogenin supra-molecular assembly in vitro compared with the architecture of the forming enamel matrix. Cells Tissues Organs. 2005;181(3-4):202-218.
77. Wang L, Guan X, Yin H, Moradian-Oldak J, Nancollas GH. Mimicking the self-organized microstructure of tooth enamel. J Phys Chem C Nanomater Interfaces. 2008;112(15):5892-5899.

78. Uskokovic V, Kim MK, Li W, Habelitz S. Enzymatic processing of amelogenin during continuous crystallization of apatite. J Mater Res. 2008;23(12):3184-3195.

79. Tarasevich BJ, Lea S, Bernt W, Engelhard M, Shaw WJ. Adsorption of amelogenin onto self-assembled and fluoroapatite surfaces. $J$ Phys Chem B. 2009;113(7):1833-1842.

80. Tarasevich BJ, Lea S, Bernt W, Engelhard MH, Shaw WJ. Changes in the quaternary structure of amelogenin when adsorbed onto surfaces. Biopolymers. 2009;91(2):103-107.

81. Fan D, Du C, Sun Z, Lakshminarayanan R, Moradian-Oldak J. In vitro study on the interaction between the $32 \mathrm{kDa}$ enamelin and amelogenin. J Struct Biol. 2009;166(1):88-94.

82. Fan Y, Sun Z, Moradian-Oldak J. Controlled remineralization of enamel in the presence of amelogenin and fluoride. Biomaterials. 2009; 30(4):478-483.

83. Zhou B, Liu Y, Wei W, Mao J. GEPIs-HA hybrid: a novel biomaterial for tooth repair. Med Hypotheses. 2008;71(4):591-593.

84. Yesil ZD, Alapati S, Johnston W, Seghi RR. Evaluation of the wear resistance of new nanocomposite resin restorative materials. J Prosthet Dent. 2008;99(6):435-443.

85. Korkmaz Y, Ozel E, Attar N, Aksoy G. The influence of one-step polishing systems on the surface roughness and microhardness of nanocomposites. Oper Dent. 2008;33(1):44-50.

86. Koh R, Neiva G, Dennison J, Yaman P. Finishing systems on the final surface roughness of composites. J Contemp Dent Pract. 2008; 9(2):138-145.

87. Turkun LS, Celik EU. Noncarious class V lesions restored with a polyacid modified resin composite and a nanocomposite: a two-year clinical trial. J Adhes Dent. 2008;10(5):399-405.

88. Manchorova NA, Vladimirov SB, Donencheva ZK, et al. A study of post-operative sensitivity in class I and class II restorations with selfetching adhesive and nanofilled composite. Folia Med (Plovdiv). 2006; 48(2):63-69.

89. Zhou G, Li Y, Xiao W, et al. Synthesis, characterization, and antibacterial activities of a novel nanohydroxyapatite/zinc oxide complex. $J$ Biomed Mater Res A. 2008;85(4):929-937.

90. Beniash E, Simmer JP, Margolis HC. The effect of recombinant mouse amelogenins on the formation and organization of hydroxyapatite crystals in vitro. J Struct Biol. 2005;149(2):182-190.

91. Bouropoulos N, Moradian-Oldak J. Analysis of hydroxyapatite surface coverage by amelogenin nanospheres following the Langmuir model for protein adsorption. Calcif Tissue Int. 2003;72(5):599-603.
Clinical, Cosmetic and Investigational Dentistry

\section{Publish your work in this journal}

Clinical, Cosmetic and Investigational Dentistry is an international, peer-reviewed, open access, online journal focusing on the latest clinical and experimental research in dentistry with specific emphasis on cosmetic interventions. Innovative developments in dental materials, techniques and devices that improve outcomes

\section{Dovepress}

and patient satisfaction and preference will be highlighted. The manuscript management system is completely online and includes a very quick and fair peer-review system, which is all easy to use. Visit http://www.dovepress.com/testimonials.php to read real quotes from published authors. 